\title{
Impacto da sustentabilidade econômico-financeira no desenvolvimento dos municípios da região da AMOSC
}

\author{
Méroli Saccardo dos Santos \\ Mestranda em Administração na Universidade do Oeste de Santa Catarina (UNOESC - CHAPECÓ/SC). \\ Endereço para contato: Rua Avenida Brasil, 1750 - Centro - Sertão - RS \\ CEP: 99170-000 - E-mail: meroli.santos@erechim.ifrs.edu.br
}

\section{Andrezza Aparecida Saraiva Piekas}

Mestranda em Administração na Universidade do Oeste de Santa Catarina (UNOESC - CHAPECÓ/SC). Endereço para contato: Rua Polidoro de Almeida Melo, 73D - Bela Vista - Chapecó - SC

CEP: 89804-280 - E-mail: andi@unochapeco.edu.br

\section{Rógis Juarez Bernardy}

Professor no Mestrado Profissional em Administração na Universidade do Oeste de Santa Catarina (UNOESC CHAPECÓ/SC).

Endereço para contato: Rua Quintino Bocaiuva, 148D - Centro - Chapecó - SC

CEP: 89801-080 - E-mail: rogis.bernardy@unoesc.edu.br

\section{Simone Sehnem}

Professora no Mestrado Profissional em Administração na Universidade do Oeste de Santa Catarina (UNOESC CHAPECÓ/SC).

Endereço para contato: Rua Índio Conda - 1178E, Edifício Ilha de Creta - Presidente Médici - Chapecó - SC

CEP: 89801-131 - E-mail: simone.sehnem@unoesc.edu.br

Recebido em 18 de julho de 2014. Aceito em 09 de novembro de 2014.

\section{Resumo}

Este estudo buscou identificar o nível de desenvolvimento frente à problemática da sustentabilidade econômico-financeira de quatro municípios selecionados na região da AMOSC. Além disso, visa identificar a dependência econômico-financeira destes municípios frente às transferências governamentais relacionando o nível de desenvolvimento municipal de acordo com o grau de dependência de recursos. $\mathrm{O}$ estudo consiste em uma pesquisa cuja abordagem é exploratória e descritiva, com enfoque quantitativo e com relação aos procedimentos consiste em um estudo de múltiplos casos, com a análise de dados secundários. Constatou-se que existe um viés entre o nível de dependência e o desenvolvimento de cada um destes municípios, aqueles com maiores volumes de transferências, majoritariamente possuem maior nível de desenvolvimento. Constatou-se, sobretudo, que apesar de haver relação direta entre as variáveis, essa condição não se sustenta ao longo do tempo em função de que cada município tem suas particularidades. O estudo indica que o desenvolvimento não se cristaliza por ações articuladas isoladamente, mas a partir da soma de ações canalizadas localmente, de forma sistemática as quais implicam na modificação da estrutura socioeconômica regional. 
Palavras-Chave

Desenvolvimento Regional; Autonomia Econômica Financeira; Transferências Intergovernamentais.

\begin{abstract}
This study sought to identify the development level of problems facing from economic and financial sustainability from four selected municipalities at the AMOSC region. Furthermore, we sought to identify the economic and financial dependency from municipalities across government transfers according the municipal degree of resource dependence development level. The study consists of a exploratory and descriptive survey and quantitative approach with regard to procedures, consists of a multiple study case with secondary analysis data. It was found that there is a bias between the level of dependence and the development of these counties, where the municipalities with higher volumes of shipments, mostly are those with higher levels of development. It was demonstrated, in particular, that although there is a direct relationship between the variables, this condition does not hold up over time according to each municipality own peculiarities. The study indicates that the development does not clump by articulated alone actions, but from the sum of locally channeled systematically actions which imply the modification of regional socio-economic structure.
\end{abstract}

\title{
Keywords
}

Regional Development; Financial Economic Autonomy; Intergovernmental Transfers;

\section{INTRODUÇÃO}

O desencadeamento de diversas mudanças na estrutura política brasileira no período pós-constituição fez surgir um arcabouço de políticas voltadas ao desenvolvimento regional. A instituição dos municípios como ente federativo os permitiu reger-se de forma autônoma, descentralizada e capaz de mobilizar a articulação de diferentes agentes em prol de um objetivo comum. De acordo com a Constituição de 1988, o ordenamento do território assim como seu controle e uso é de competência municipal. Contudo, há uma fragilidade ainda questionada sobre estes novos arranjos organizacionais.

Neste contexto, pode-se observar que os municípios vêm assumindo crescente importância no tocante à formulação de políticas de desenvolvimento local que refletem no regional. Apesar do grande avanço destas políticas (principalmente sociais), observa-se ainda que seus resultados estejam aquém dos esperados. Em poucos casos há uma ação concreta no sentido de transformar estas regiões, pela dificuldade de concretização de projetos públicos.

Um dos entraves ao desenvolvimento pode ser explicado pelo nível de autonomia financeira dos municípios. Nesse sentido, aqueles municípios com alta dependência de transferências intergovernamentais têm maiores dificuldades de atuação local, ficando condicionados a projetos de interesse do governo federal, mesmo que estes não atendam necessariamente ao apelo local. Dessa forma, surge a necessidade de identificar o grau de dependência econômico financeira no tocante às transferências intergovernamentais de cada um dos municípios estudados (SANTOS, 2009). 
Neste contexto, o objetivo principal deste estudo é identificar o nível de desenvolvimento regional frente à problemática da sustentabilidade econômico-financeira de quatro municípios selecionados dentre os vinte que compõem a Associação dos Municípios do Oeste de Santa Catarina - AMOSC. Possui ainda como objetivo, identificar a dependência econômico-financeira destes municípios frente às transferências governamentais relacionando o nível de desenvolvimento municipal de acordo com o grau de dependência de recursos.

A justificativa para a realização desta investigação se fundamenta pela importância do tema, tendo em vista a necessidade dos municípios em potencializar suas ações de desenvolvimento com vistas à ampliação do controle de suas contas, pois a arrecadação própria é a forma mais segura de sustentar os gastos públicos ao longo do tempo, garantindo melhores resultados no que diz respeito aos projetos de interesse local (SANTOS, 2009).

Como síntese metodológica, destaca-se que este estudo se insere em uma abordagem exploratória e descritiva com enfoque de pesquisa quantitativa. Em relação à estratégia metodológica optou-se pelo estudo de múltiplos casos, com base em quatro pequenos municípios da região da AMOSC. Neste sentido, considerar-se que os municípios enfrentam um problema que pode ser limitador deste desenvolvimento que é o grau de dependência de recursos intergovernamentais. Entender esta relação é de extrema relevância, pois com estas respostas é possível minimizar os erros na criação de políticas públicas adaptando-as às realidades locais.

O artigo está estruturado em quatro seções, além desta introdução: uma discussão conceitual sobre o desenvolvimento regional, a autonomia dos municípios no tocante à transferência de recursos intergovernamentais; os procedimentos metodológicos aplicados no estudo; a análise dos dados do estudo e as evidências e conclusão do estudo.

\section{O DESENVOLVIMENTO SOB O ENFOQUE DOS MUNICÍPIOS}

Ao constituir os municípios como entes federativos, a Constituição de 1988 permitiu aos gestores municipais assumir um papel de articulação local e regional a fim de promover o desenvolvimento das regiões sem, sobretudo depender exclusivamente dos anseios do Estado e da União, possibilitando a criação de um mecanismo de geração de competitividade local, na construção de novas políticas de desenvolvimento regional.

A possibilidade do uso da competência municipal fez surgir um arcabouço de políticas voltadas ao desenvolvimento regional, em especial pela observação das disparidades ou assimetrias regionais. Filippim e Abrucio (2010) destacam que a discussão acerca do assunto é por vezes polêmica justamente pelos diversos atores envolvidos interpretar tais discussões de forma descompassada.

O relato de Cândido (2002) destaca a necessidade de um ambiente favorável promovido pelo Estado que pode fomentar a geração do desenvolvimento ao se coligar com atores chaves de cada comunidade. No entanto, o problema é que muitas vezes a coalizão impede o ganho da coletividade e pior ainda, o envolvimento da sociedade local de forma participativa.

Econ. e Desenv., Santa Maria, vol. 26, n.2, p. 56 - 73, jul. - dez. 2014 
Não bastassem os problemas relacionados à criação e aplicação das políticas de desenvolvimento regional, insere- se na questão os diferentes contextos de desenvolvimento. Siedenberg (2004, p. 1), afirma que apesar dos expressivos debates acerca do tema, nas últimas décadas, em especial nos debates de cunho político público, o desenvolvimento ainda é um termo impreciso, "nunca houve unanimidade em torno desse conceito e, principalmente, sobre como pode e deve ser fomentado". Deve-se levar em conta que o desenvolvimento é um processo de mudança que implica em questões políticas, socioculturais e econômicas.

Especificamente para a região deste estudo, entendem-se como elementos catalizadores do desenvolvimento a implantação de políticas públicas que promovem a diversificação das atividades econômicas, a formação de redes de produção e comercialização, a inovação, a infraestrutura adequada, a participação social nas decisões, entre outros.

Siedenberg (2006) contribui ao mencionar que o desenvolvimento regional diz respeito às mudanças ocorridas em um determinado espaço, mesmo que seus reflexos estabeleçam inter-relações. Bugs (2011), considera o desenvolvimento regional resultado da otimização processual e da regular utilização de recursos de uma região, medido por meio da correta execução de políticas locais integradas com as políticas regionais, estaduais e federais.

Lopes (1995) afirma que a razão determinante do crescente interesse em estudar o desenvolvimento regional, está na necessidade de elaborar políticas públicas, que possam atender necessidades mútuas usuais em um contexto de diversidade espacial. Bruna (2012) destaca que os arranjos produtivos locais (APL's), são uma maneira produtiva e econômica de promover o desenvolvimento regional.

Outra questão a ser observada são os diferentes recortes regionais existentes. Segundo Corrêa (1997, p.45), os geógrafos se utilizaram de três grandes interpretações para designar região, "região natural [...], região paisagem [...] e região como criação intelectual [...]. Após 1970, existiu grande pluralismo conceitual em relação ao conceito de região, baseado na diferenciação de áreas". Benko (1999, p. 20) concorda com a mesma linha de pensamento: "a evolução da noção de região, no século $\mathrm{XX}$, fez os economistas, os geógrafos, os historiadores e os sociólogos compreenderem que a região é um produto social gradualmente construído por sociedades, nos respectivos espaços de vida". Neste sentido contribuem Filippim e Rótulo (2013) ao afirmarem que "a delimitação de região pode assumir diferentes contornos e inserir elementos naturais, culturais, políticos, administrativos".

Em Santa Catarina há uma numerosa série de divisões, Filippim e Rótulo (2013, p. 53) destacam as "Associações de Municípios; Fóruns, Agências de desenvolvimento, Secretarias de Desenvolvimento Regional” entre outros específicos para cada área, que dificultam que ações de desenvolvimento sejam canalizadas, inclusive contribuem para a sobreposição de políticas públicas.

O estudo de Nadal e Bernardy (2002) destaca a importância da divisão territorial, e enfatizam o quanto importante seria se todas as instituições que se relacionam com o desenvolvimento regional, se utilizassem da mesma divisão territorial. Nesta mesma perspectiva, contribuem Filippim e Rótulo (2013), quando destacam em seu estudo sobre governança e diálogo federativo, "que região"? A região fundamentada num viés teórico ou 
aquela imposta por políticas setoriais? Ora, havendo discordância, incerteza e subjetividade conceitual, como não haver complexidade na elaboração e condução das políticas?

O que precisa ser impulsionado é a efetiva participação da sociedade como promotora do desenvolvimento regional. Becker (2002) menciona estratégias bem sucedidas que neste contexto estão associadas às vontades coletivas regionais, fundamentadas pelos diferentes agentes. $\mathrm{O}$ desenvolvimento regional é o resultado de um conjunto de ações voltadas às especificidades locais, sendo então fundamental a interação e a participação da comunidade, com o objetivo de potencializar aquilo que cada uma tem de melhor, e buscar soluções para resolver as situações mais críticas. Bugs (2011) salienta que, no entanto, se observa que dificuldades aliadas às necessidades urgentes acabam fomentando decisões impulsivas que apenas amenizam situações de curto prazo, logo a importância de definir, planejar, organizar, implementar e controlar sistemas adequados de gestão pública para a realidade local.

É importante lembrar que o desenvolvimento regional é um movimento integrado que traz mudanças que implicam não somente em fatores econômicos, mas políticos e culturais de uma sociedade. Para Siedenberg (2006), no entanto, existem particularidades que exigem diferentes necessidades, as quais provocam o desenvolvimento em diferentes períodos de tempo e espaço, supondo diferentes localidades.

Siedenberg (2006) destaca que o desenvolvimento regional provoca uma série de mudanças configurando-se assim um complexo sistema de interações e inter-relações. Ainda segundo o autor, o termo desenvolvimento regional aponta a posição de uma região no tocante aos indicadores socioeconômicos, comparados a outras regiões em certa temporalidade, logo, "são explicitadas apenas algumas características de um determinado momento do processo de mudanças" (SIEDENBERG, 2006, p. 72).

Pode-se compreender com base em Orlowski (2013), que o desenvolvimento regional fundamenta-se em atender as especificidades locais, de cunho interdisciplinar sendo fundamental a interação da comunidade, na busca conjunta de soluções para os pontos críticos, bem como na perspectiva de potencializar os pontos positivos. No entanto, há um problema em virtude das desigualdades regionais, as quais acabam por afastar a comunidade local para centros maiores em busca de oportunidades e empregos e renda. Neste sentido, amplia-se a responsabilidade dos governos locais.

Por um lado, estes fenômenos também se manifestam no ambiente deste estudo, uma vez que os fluxos regionais de pessoas, financeiros, de potenciais humanos, se concentram em determinados locais (polos), em detrimento da formação de vazios (pequenos municípios), contribuindo para acentuar as assimetrias regionais. Por outro, o desenvolvimento tem sido o principal objetivo das políticas públicas regionais, atrair novos investimentos faz parte do processo de desenvolvimento das regiões, as características locais podem influenciar as decisões locacionais por parte dos agentes econômicos, o que estimula novos processos de desenvolvimento, a partir da atuação dos atores locais, como também na atração de novos agentes.

A inserção de novos agentes na busca pelo desenvolvimento de uma região, pode não significar obtenção de resultados efetivos, no entanto, viabilizam novos debates capazes de mediar à relação entre desejos individuais, necessidades coletivas, interesses políticos, interesses privados, enfim, diversas situações associadas a um conjunto de decisões. 
Os municípios que fazem parte deste estudo se caracterizam pela baixa densidade demográfica, com perspectiva de estabilização e retração populacional, inclusive urbana, homogeneização das atividades econômicas, atividades econômicas urbanas estáticas, como no comércio e atividades industriais dispersas.

Entretanto, se reconhece que nos pequenos municípios existem potenciais de desenvolvimento pela menor burocratização das políticas públicas, assim como pela facilitação dos fluxos de informações, maior abrangência territorial das políticas públicas e efetividade das mesmas. Os municípios de Águas de Chapecó, Formosa do Sul, Nova Erechim e União do Oeste, são pertencentes à região da $\mathrm{AMOSC}^{1}$, que segundo o IBGE (2014) está localizada na mesorregião Oeste Catarinense, no estado de Santa Catarina. A população residente nestes municípios totalizou 16.295 habitantes, em 2013, de acordo com a estimativa do IBGE (2014), o conjunto destes municípios possui $397.446 \mathrm{~km}^{2}$, e detêm $5,48 \%$ dos habitantes da região, a densidade demográfica média é de $41,75 \mathrm{hab} / \mathrm{km}^{2}$.

Quadro 1: Apresentação dos municípios

\begin{tabular}{|c|c|c|}
\hline Município & Aspectos Populacionais & Principais atividades econômicas \\
\hline Águas de Chapecó & $\begin{array}{lll}\text { População de } 6.313 & \text { habitantes e } \\
\text { densidade } & \text { demográfica de } 43,70 \\
\text { hab/Km } & \end{array}$ & $\begin{array}{l}\text { Destaca-se pela produção agrícola, pecuária e } \\
\text { fruticultura. }\end{array}$ \\
\hline Formosa do Sul & $\begin{array}{lll}\text { População } & \text { de } 2.603 \text { habitantes e } \\
\text { densidade } & \text { demográfica de } 25,98 \\
\text { hab/Km } & & \end{array}$ & Destaca-se pela produção agrícola. \\
\hline Nova Erechim & $\begin{array}{lll}\text { População } & \text { de } 4.577 \text { habitantes e } \\
\text { densidade } & \text { demográfica de } 65,88 \\
\text { hab/Km } & & \end{array}$ & Destaca-se pela produção agropecuária. \\
\hline União do Oeste & $\begin{array}{lll}\text { População de } 2.802 & \text { habitantes e } \\
\text { densidade } & \text { demográfica de } 31,42 \\
\text { hab/Km } & \end{array}$ & Destaca-se pela produção agropecuária. \\
\hline
\end{tabular}

Fonte: Elaborado pelos autores com base nos dados do IBGE, 2014.

Ao observar o quadro 1, percebe-se a existência de municípios de pequeno porte, considerando o tamanho populacional, com atividades rurais, como principais atividades econômicas, todos são polarizados pela cidade de Chapecó, se considerar a funcionalidade desta região.

\section{PROCEDIMENTOS METODOLÓGICOS}

Com base nos objetivos deste estudo, optou-se pela realização de um estudo de múltiplos casos, sendo este estudo exploratório e descritivo. De acordo com Yin (2001), o estudo de caso se caracteriza em função do pouco controle que o pesquisador exerce sobre os eventos, em especial quando o foco do mesmo se encontra em fenômenos contemporâneos da

\footnotetext{
${ }^{1}$ A AMOSC é uma entidade municipalista, mantida exclusivamente com recursos dos municípios, que apoia os consorciados como um órgão prestador de serviços em projetos, consultoria e assessoramento técnico municipal, sendo composta por vinte municípios.
} 
vida real. Ainda segundo o autor, utiliza-se o estudo de caso em situações como "[...] pesquisa de planejamento regional e municipal, [...] ou instituições públicas [...]” (YIN, 2001, p. 20).

A investigação é exploratória, pois busca conhecer o panorama dos municípios estudados. Cervo e Bervian (1996) dizem que uma pesquisa exploratória visa caracterizar, classificar e definir um problema. Segundo Marconi e Lakatos (2003) a pesquisa exploratória é desenvolvida na intenção de proporcionar visão geral, de tipo aproximativo acerca de determinado fato. É descritiva, pois descreve fatos e fenômenos de determinada realidade. De acordo com Marconi e Lakatos (2003) a pesquisa descritiva tem por objetivo estudar as características de um grupo, ou comunidade. A figura 1 apresenta as etapas realizadas para construção do estudo.

Figura 1: Fluxograma das etapas da pesquisa

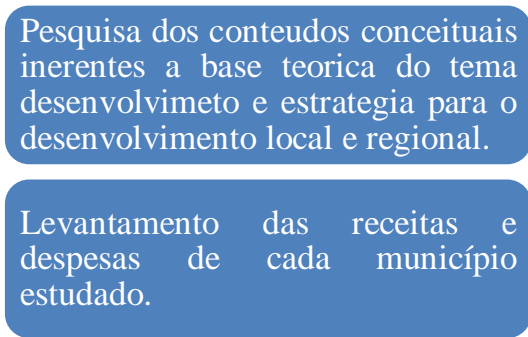

Levantamento do número de habitantes de cada município no período de 2010 a 2013 .
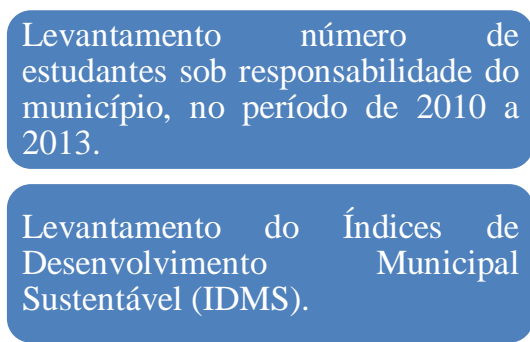

Consolidação e sistematização dos dados levantados.

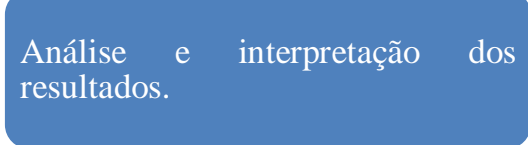

- Consulta a artigos, publicações e livros a cerca dos assuntos abordados.

- Coleta de dados junto ao Tribunal de Contas do Estado de Santa Catarina (TCE).

- Coleta de dados junto ao Instituto Brasileiro de Geografia e Estatística (IBGE).

- Coleta de dados junto ao Instituto Nacional de Estudos e Pesquisas Educacionais Anísio Teixeira (INEP)

- Informações coletadas no Sistema de Indicadores de Desenvolvimento Municipal Sustentável - FECAM.

- Tratamento destes dados remetendo à dinâmica quantitativa da pesquisa, ou seja, tratamento estatístico.

- Mediante análise das relações, pois, estabelece conexões entre os elementos do texto, permitindo verificar a coerência entre os elementos do texto e o tema (MARCONI; LAKATOS 2003).

Fonte: Elaborado pelos autores

A pesquisa foi realizada nos meses de maio e junho de 2014, nos municípios de Águas de Chapecó, Formosa do Sul, Nova Erechim e União do Oeste. O critério de seleção das unidades de estudo deve considerar características singulares, estarem envolvidos em experiências similares e serem representativos (BUGS, 2011). Neste sentido a seleção dos municípios se deu em função da tipologia espacial dos mesmos, todos compõem a região da AMOSC, sendo que se caracterizam segundo Bernardy, Zuanazzi e Monteiro (2008), por apresentarem cenários de desvitalização populacional com pequena dinâmica econômica 
local. Este estudo é um projeto piloto onde propositalmente os municípios escolhidos para análise não possuem continuidade geográfica, entretanto, fazem parte da região da AMOSC.

Quanto à abordagem metodológica, este estudo classifica-se como quantitativo em função de considerar dados secundários. A metodologia utilizada inclui o levantamento de dados relativos aos volumes de recursos repassados pelos governos estadual e federal, no período de 2010 a 2013, e a composição destes valores na receita total dos municípios de Águas de Chapecó, Formosa do Sul, Nova Erechim e União do Oeste. São elencadas, também as despesas de cada município relacionando o volume de despesas com as áreas de educação e saúde.

Gil (2010) enfatiza que o elemento mais importante da fase de delineamento é a coleta de dados. Neste estudo foram utilizados dados secundários obtidos junto ao Portal do Cidadão do Tribunal de Contas do Estado de Santa Catarina (2014), Atlas do desenvolvimento Humano no Brasil (2013) e a partir de pesquisa bibliográfica, sendo que tanto os dados relativos às receitas e despesas municipais quanto os índices de desenvolvimento foram pesquisados, no período de 2010 a 2013.

\section{APRESENTAÇÃO E ANÁLISE DOS DADOS}

Com vistas a proporcionar uma melhor organização dos dados coletados e analisados, esta seção contém cinco subdivisões: primeiro apresenta-se uma breve caracterização da Associação dos Municípios do oeste de Santa Catarina (AMOSC), a qual os municípios estudados são pertencentes (4.1); em seguida, apresenta-se os dados que caracterizam o grau de dependência econômico-financeira destes municípios frente às transferências governamentais (4.2); na sequência foi realizado o relacionamento do nível de desenvolvimento municipal com o grau de dependência de recursos (4.3) e por fim, apresentase a discussão dos resultados a partir das análises realizadas de acordo com os objetivos do estudo (4.4).

\subsection{Caracterização da AMOSC}

Em 1968 foi criada a Associação dos Municípios do Oeste de Santa Catarina AMOSC. Segundo o IBGE (2014), a AMOSC (Mapa 1) está localizada na microrregião de Chapecó, que compõem a mesorregião Oeste Catarinense, no Estado de Santa Catarina, abrangendo uma área de 2.955,6 $\mathrm{km}^{2}$. O propósito da Associação é defender os interesses institucionais de seus vinte municípios consorciados, sendo estes, Águas de Chapecó, Águas Frias, Caxambu do Sul, Chapecó, Cordilheira Alta, Coronel Freitas, Formosa do Sul, Guatambu, Irati, Jardinópolis, Nova Erechim, Nova Itaberaba, Planalto Alegre, Pinhalzinho, Quilombo, Santiago do Sul, São Carlos, Serra Alta, Sul Brasil e União do Oeste (AMOSC, 2014).

Segundo dados do IBGE (2014), a população total estimada destes municípios, em 2013, era de 297.310 pessoas, registrando uma densidade demográfica de $53,47 \mathrm{hab} / \mathrm{km}^{2}$. É 
importante salientar que $67 \%$ desta população está localizada no município de Chapecó, visto por suas características geográficas e populacionais atípico. Desconsiderando este município, a densidade demográfica da região cai para $40,85 \mathrm{hab} / \mathrm{km}^{2}$, sendo que alguns municípios registram números significativamente inferiores, o menor deles é o município de Santiago do Sul.

De acordo com dados da Federação Catarinense de Municípios - FECAM (2014), as principais atividades econômicas desenvolvidas na região da AMOSC estão relacionadas à agropecuária, desde o cultivo voltadas para a alimentação dos animais até a industrialização que tem na agroindústria de transformação de carnes seu maior potencial econômico.

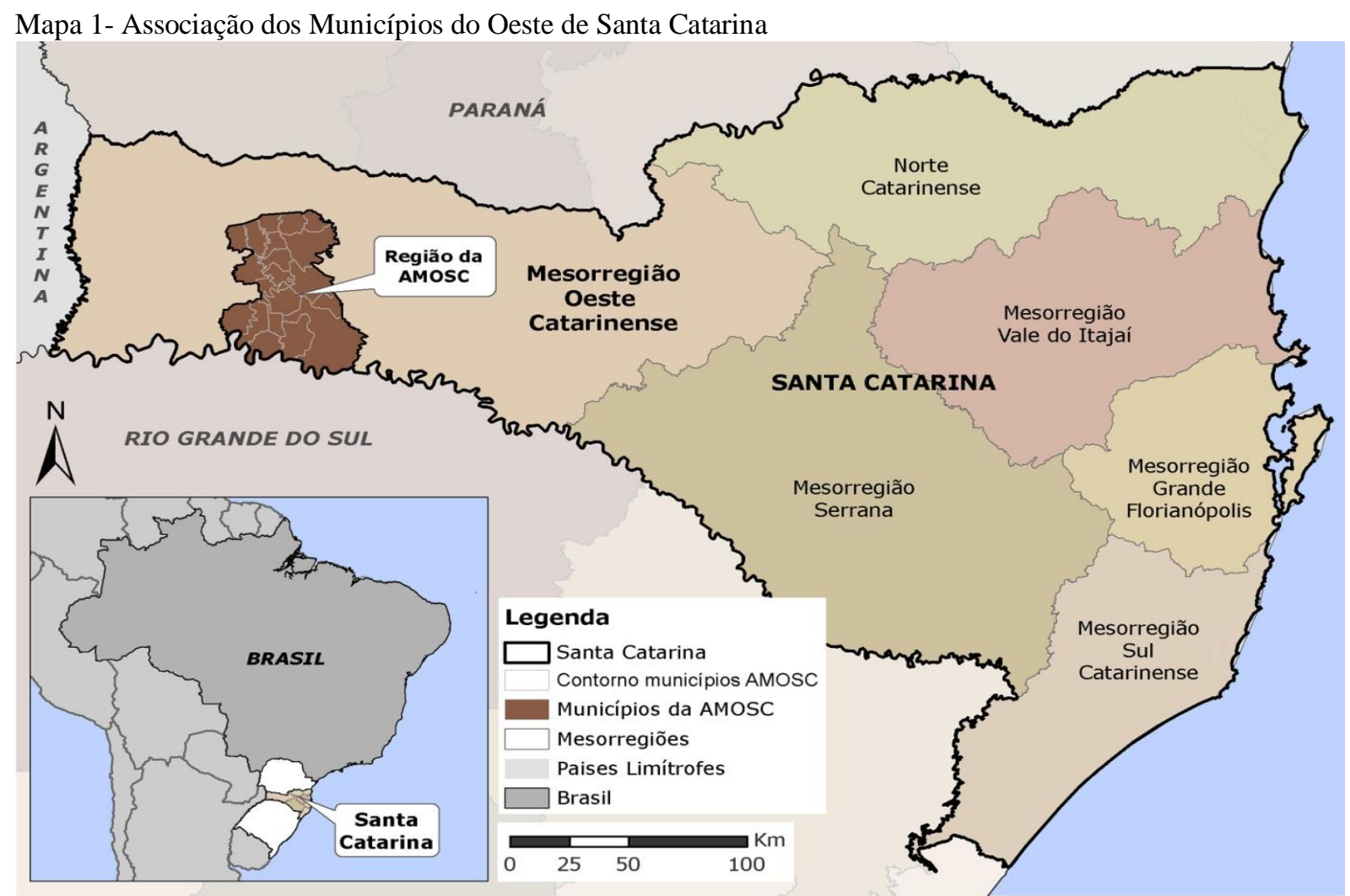

Fonte: IBGE, 2010.

\subsection{Dependência econômico-financeira destes municípios frente às transferências governamentais}

Com vistas a demonstrar os resultados, buscou-se sintetizar as informações coletadas em tabelas de modo a melhorar a leitura e interpretação dos dados. Anteriormente aos dados em si, apresenta-se um quadro síntese expondo a natureza das receitas. 
Quadro 1- Natureza das receitas municipais

\begin{tabular}{|c|c|}
\hline Tipo de Receita & Natureza \\
\hline Receita Tributária & $\begin{array}{l}\text { Decorrente da competência de tributar do município, sendo composta por } \\
\text { impostos, taxas e contribuições de melhoria. }\end{array}$ \\
\hline Receitas de Contribuições & $\begin{array}{l}\text { Decorrente das contribuições sociais e das contribuições econômicas, sendo que } \\
\text { os municípios podem instituir contribuição, cobrada de seus servidores, para o } \\
\text { custeio, em beneficio destes, de sistemas de previdência e assistência social. }\end{array}$ \\
\hline Receita Patrimonial & $\begin{array}{l}\text { Decorrente do resultado financeiro da ocupação dos bens públicos, mobiliários } \\
\text { ou imobiliários ou da participação societária. }\end{array}$ \\
\hline Receita de Serviços & $\begin{array}{l}\text { Decorrente da prestação de serviços como transporte, comunicação, saúde, } \\
\text { agropecuários dentre outros. }\end{array}$ \\
\hline Transferências Correntes & $\begin{array}{l}\text { Decorrente de receitas recebidas de outras pessoas de direito público ou } \\
\text { privado, independentemente de contraprestação direta de bens e serviços. }\end{array}$ \\
\hline Receita Agropecuária & $\begin{array}{l}\text { Decorrente de atividades ou exploração agropecuária, tais como as produções } \\
\text { vegetais e animal e seus derivados, bem como atividades de beneficiamento ou } \\
\text { transformação desses produtos em instalações existentes nos próprios } \\
\text { estabelecimentos. }\end{array}$ \\
\hline Outras receitas Correntes & $\begin{array}{l}\text { Decorrentes da arrecadação de multas, juros, restituições, indenizações, receita } \\
\text { da cobrança da dívida ativa, aplicações financeiras e outras. }\end{array}$ \\
\hline Operações de Crédito & Decorrente de empréstimos e financiamentos, ou seja, da constituição de dívida. \\
\hline Alienação de Bens & Decorrente da venda de bens e direitos. \\
\hline $\begin{array}{l}\text { Amortização de } \\
\text { Empréstimos }\end{array}$ & $\begin{array}{l}\text { Decorrente do recebimento de valores anteriormente emprestados a outras } \\
\text { entidades de direito público. }\end{array}$ \\
\hline Transferência de Capital & $\begin{array}{l}\text { Decorrente do recebimento de valores de outras pessoas de direito público ou } \\
\text { privado destinados a atender despesas de capital. }\end{array}$ \\
\hline Outras Receitas de Capital & $\begin{array}{l}\text { Decorrente de valores arrecadados com outras receitas vinculadas ao acréscimo } \\
\text { patrimonial da unidade, não enquadradas nas fontes dispostas na Portaria STN n } \\
350 \text {, de } 18 \text { de Junho de } 2010 \text {. }\end{array}$ \\
\hline
\end{tabular}

Fonte: Elaborado pelos autores com base em BRASIL (2010), Secretaria do Tesouro Nacional. Portaria $\mathrm{n}^{\circ} 350$

Para possibilitar a comparação entre receitas próprias e receitas advindas de transferências intergovernamentais estão relacionadas, na Tabela 1, todas as receitas arrecadadas pelos municípios em análise, no período de 2010 a 2013.

Tabela 1 - Receitas recebidas pelos municípios classificadas por subcategoria econômica: 2010/2013

\begin{tabular}{|c|c|c|c|c|c|}
\hline \multicolumn{6}{|c|}{ RECEITA POR SUBCATEGORIA ECONÔMICA } \\
\hline MUNICÍPIO & TIPO DE RECEITA & 2010 & 2011 & 2102 & 2013 \\
\hline \multirow{10}{*}{ 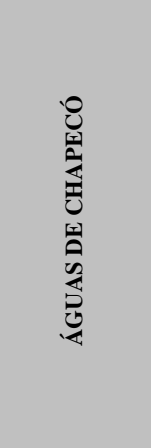 } & Receita Tributária & $\mathrm{R} \$ 1.900 .948,74$ & $\mathrm{R} \$ 1.998 .111,49$ & $\mathrm{R} \$ 455.305,61$ & $\mathrm{R} \$ 727.591,61$ \\
\hline & Receitas de Contribuições & - & $\mathrm{R} \$ 6.652,02$ & $\mathrm{R} \$ 2.185,99$ & $\mathrm{R} \$ 130.947,65$ \\
\hline & Receita Patrimonial & - & $\mathrm{R} \$ 116.827,86$ & $\mathrm{R} \$ 72.407,43$ & $\mathrm{R} \$ 33.603,48$ \\
\hline & Receita de Serviços & - & $\mathrm{R} \$ 126.699,25$ & $\mathrm{R} \$ 53.165,61$ & $\mathrm{R} \$ 136.358,74$ \\
\hline & Transferências Correntes & $\mathrm{R} \$ 6.988 .833,63$ & $\mathrm{R} \$ 10.045 .277,80$ & $\mathrm{R} \$ 10.566 .058,82$ & $\mathrm{R} \$ 11.254 .193,22$ \\
\hline & Outras Receitas Correntes & - & $\mathrm{R} \$ 309.689,88$ & $\mathrm{R} \$ 45.263,67$ & $\mathrm{R} \$ 250.664,47$ \\
\hline & Alienação de Bens & - & $\mathrm{R} \$ 135.600,00$ & $\mathrm{R} \$ 162.500,00$ & - \\
\hline & Amortização de Empréstimos & - & $\mathrm{R} \$ 9.308,93$ & $\mathrm{R} \$ 21.644,58$ & $\mathrm{R} \$ 45.463,17$ \\
\hline & Transferências de Capital & - & $\mathrm{R} \$ 790.567,36$ & $\mathrm{R} \$ 1.475 .269,46$ & $\mathrm{R} \$ 960.212,73$ \\
\hline & TOTAL DA RECEITA ARRECADADA & $\mathbf{R} \$ 8.889 .782,37$ & $\mathbf{R} \$ 13.538 .734,59$ & $\mathbf{R} \$ 12.853 .801,17$ & $\mathbf{R} \$ 13.539 .035,07$ \\
\hline
\end{tabular}




\begin{tabular}{|c|c|c|c|c|c|}
\hline \multirow{13}{*}{ 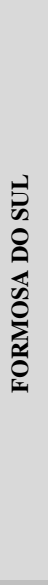 } & Receita Tributária & $\mathrm{R} \$ 207.330,40$ & $\mathrm{R} \$ 380.167,77$ & $\mathrm{R} \$ 390.088,28$ & $\mathrm{R} \$ 476.665,64$ \\
\hline & Receitas de Contribuições & - & $\mathrm{R} \$ 12.165,84$ & $\mathrm{R} \$ 14.545,16$ & $\mathrm{R} \$ 12.098,08$ \\
\hline & Receita Patrimonial & - & $\mathrm{R} \$ 204.701,83$ & $\mathrm{R} \$ 81.641,75$ & $\mathrm{R} \$ 35.067,87$ \\
\hline & Receita Agropecuária & - & $\mathrm{R} \$ 30.697,96$ & $\mathrm{R} \$ 23.098,33$ & $\mathrm{R} \$ 55.524,91$ \\
\hline & Receita de Serviços & - & $\mathrm{R} \$ 27.297,43$ & $\mathrm{R} \$ 19.181,71$ & $\mathrm{R} \$ 4.131,62$ \\
\hline & Transferências Correntes & $\mathrm{R} \$ 5.683 .483,23$ & $\mathrm{R} \$ 7.774 .282,71$ & $\mathrm{R} \$ 8.193 .893,21$ & $\mathrm{R} \$ 8.795 .744,02$ \\
\hline & Outras Receitas Correntes & - & $\mathrm{R} \$ 196.387,73$ & $\mathrm{R} \$ 50.999,02$ & $\mathrm{R} \$ 73.268,44$ \\
\hline & Operações de Crédito & - & - & $\mathrm{R} \$ 52.339,68$ & $\mathrm{R} \$ 348.802,44$ \\
\hline & Alienação de Bens & - & - & - & $\mathrm{R} \$ 111.633,00$ \\
\hline & Amortização de Empréstimos & - & $\mathrm{R} \$ 17.437,37$ & - & $\mathrm{R} \$ 16.275,07$ \\
\hline & Transferências de Capital & - & $\mathrm{R} \$ 283.150,34$ & $\mathrm{R} \$ 551.690,74$ & $\mathrm{R} \$ 951.058,10$ \\
\hline & Outras Receitas de Capital & - & $\mathrm{R} \$ 311,20$ & $\mathrm{R} \$ 5.111,29$ & - \\
\hline & TOTAL DA RECEITA ARRECADADA & $\mathrm{R} \$ 5.890 .813,63$ & $\mathrm{R} \$ 8.926 .600,18$ & R\$9.396.689,17 & $\mathrm{R} \$ 10.880 .269,19$ \\
\hline \multirow{11}{*}{ 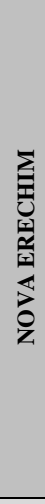 } & Receita Tributária & $\mathrm{R} \$ 461.267,59$ & $\mathrm{R} \$ 742.818,40$ & $\mathrm{R} \$ 852.258,48$ & $\mathrm{R} \$ 868.595,07$ \\
\hline & Receitas de Contribuições & - & $\mathrm{R} \$ 160.447,78$ & $\mathrm{R} \$ 171.321,15$ & $\mathrm{R} \$ 173.225,57$ \\
\hline & Receita Patrimonial & - & $\mathrm{R} \$ 39.283,60$ & $\mathrm{R} \$ 30.308,22$ & $\mathrm{R} \$ 173.225,57$ \\
\hline & Receita de Serviços & - & $\mathrm{R} \$ 72.260,92$ & $\mathrm{R} \$ 68.683,32$ & $\mathrm{R} \$ 96.353,86$ \\
\hline & Transferências Correntes & $\mathrm{R} \$ 7.927 .036,63$ & $\mathrm{R} \$ 10.241 .372,52$ & $\mathrm{R} \$ 10.541 .091,17$ & $\mathrm{R} \$ 11.969 .633,19$ \\
\hline & Outras Receitas Correntes & - & $\mathrm{R} \$ 199.895,91$ & $\mathrm{R} \$ 161.710,21$ & $\mathrm{R} \$ 219.142,10$ \\
\hline & Operações de Crédito & - & $\mathrm{R} \$ 198.000,00$ & $\mathrm{R} \$ 604.411,76$ & $\mathrm{R} \$ 83.037,98$ \\
\hline & Alienação de Bens & - & $\mathrm{R} \$ 200.764,93$ & $\mathrm{R} \$ 180.868,71$ & $\mathrm{R} \$ 68.879,65$ \\
\hline & Amortização de Empréstimos & - & $\mathrm{R} \$ 19.205,59$ & - & $\mathrm{R} \$ 15.809,50$ \\
\hline & Transferências de Capital & - & $\mathrm{R} \$ 420.673,25$ & $\mathrm{R} \$ 544.376,75$ & $\mathrm{R} \$ 282.925,00$ \\
\hline & TOTAL DA RECEITA ARRECADADA & $\mathrm{R} \$ 8.388 .304,22$ & $\mathrm{R} \$ 12.294 .722,90$ & $\mathbf{R} \$ 13.155 .029,77$ & $\mathrm{R} \$ 13.814 .242,44$ \\
\hline \multirow{11}{*}{ 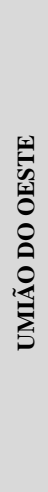 } & Receita Tributária & $\mathrm{R} \$ 231.619,52$ & $\mathrm{R} \$ 370.583,27$ & $\mathrm{R} \$ 422.282,04$ & $\mathrm{R} \$ 439.410,82$ \\
\hline & Receitas de Contribuições & - & $\mathrm{R} \$ 15.856,33$ & $\mathrm{R} \$ 16.742,87$ & $\mathrm{R} \$ 19.965,00$ \\
\hline & Receita Patrimonial & - & $\mathrm{R} \$ 63.814,87$ & $\mathrm{R} \$ 53.319,68$ & $\mathrm{R} \$ 50.299,78$ \\
\hline & Receita de Serviços & - & $\mathrm{R} \$ 116.267,26$ & $\mathrm{R} \$ 82.326,41$ & $\mathrm{R} \$ 109.818,25$ \\
\hline & Transferências Correntes & $\mathrm{R} \$ 5.927 .579,65$ & $\mathrm{R} \$ 8.038 .471,94$ & $\mathrm{R} \$ 8.620 .186,10$ & $\mathrm{R} \$ 9.475 .412,58$ \\
\hline & Outras Receitas Correntes & - & $\mathrm{R} \$ 49.139,72$ & $\mathrm{R} \$ 72.270,81$ & $\mathrm{R} \$ 56.121,10$ \\
\hline & Operações de Crédito & - & $\mathrm{R} \$ 55.999,38$ & $\mathrm{R} \$ 977.601,95$ & $\mathrm{R} \$ 24.755,35$ \\
\hline & Alienação de Bens & - & $\mathrm{R} \$ 2.149,00$ & $\mathrm{R} \$ 33.600,00$ & - \\
\hline & Amortização de Empréstimos & - & $\mathrm{R} \$ 3.058,01$ & $\mathrm{R} \$ 3.786,00$ & $\mathrm{R} \$ 3.075,57$ \\
\hline & Transferências de Capital & - & $\mathrm{R} \$ 587.096,22$ & $\mathrm{R} \$ 1.031 .389,08$ & $\mathrm{R} \$ 1.145 .039,38$ \\
\hline & TOTAL DA RECEITA ARRECADADA & R\$6.159.199,17 & $\mathbf{R} \$ 9.302 .436,00$ & R\$11.313.504,94 & R\$11.323.897,83 \\
\hline
\end{tabular}

Fonte: Elaborado pelos autores com base nos dados do Portal do Cidadão do Tribunal de Contas do Estado de Santa Catarina (2014).

A tabela 1 apresenta as fontes de recursos que compuseram as receitas dos municípios em análise no período compreendido entre os anos de 2010 a 2013. Pode-se observar, a partir da análise da tabela, que a composição das finanças destes municípios apresenta uma estrutura de receitas baseada principalmente em receitas provenientes de transferências da União e Estado, o que demonstra além da forte dependência dos municípios por recursos intergovernamentais a fragilidade destes na geração de receitas próprias.

A relevância das receitas decorrentes das transferências intergovernamentais, também pode ser verificada a partir dos dados elencados na tabela 2, onde as transferências correntes correspondem, em todos os casos, valores superiores a $70 \%$ das receitas recebidas por estes municípios, nos períodos pesquisados. 
Tabela 2 - Percentual de receitas próprias e de transferências correntes 2010/2013

\begin{tabular}{|c|c|c|c|c|c|c|c|c|c|c|c|c|c|}
\hline Município & Tipo de Receita & & 2010 & $\%$ & & 2011 & $\%$ & & 2012 & $\%$ & & 2013 & $\%$ \\
\hline \multirow{3}{*}{$\begin{array}{l}\text { Águas de } \\
\text { Chapecó }\end{array}$} & Receitas Próprias & $\mathrm{R} \$$ & $1.900 .948,74$ & $21,40 \%$ & $\mathrm{R} \$$ & $2.702 .889,43$ & $20,00 \%$ & $\mathrm{R} \$$ & $812.472,89$ & $6,30 \%$ & $\mathrm{R} \$$ & $1.324 .629,12$ & $9,80 \%$ \\
\hline & $\begin{array}{l}\text { Receitas de } \\
\text { Transferência }\end{array}$ & $\mathrm{R} \$$ & $6.988 .833,63$ & $78,60 \%$ & $\mathrm{R} \$$ & $10.835 .845,16$ & $80,00 \%$ & $\mathrm{R} \$$ & $12.041 .328,28$ & $93,70 \%$ & $\mathrm{R} \$$ & $12.214 .405,95$ & $90,20 \%$ \\
\hline & $\begin{array}{l}\text { Total da Receita } \\
\text { Arrecadada }\end{array}$ & $\mathrm{R} \$$ & $8.889 .782,37$ & $100 \%$ & $\mathrm{R} \$$ & $13.538 .734,59$ & $100 \%$ & $\mathrm{R} \$$ & $12.853 .801,17$ & $100 \%$ & $\mathrm{R} \$$ & $13.539 .035,07$ & $100 \%$ \\
\hline \multirow{3}{*}{$\begin{array}{c}\text { Formosa } \\
\text { do Sul }\end{array}$} & Receitas Próprias & $\mathrm{R} \$$ & $207.330,40$ & $3,50 \%$ & $\mathrm{R} \$$ & $869.167,13$ & $9,70 \%$ & $\mathrm{R} \$$ & $637.005,22$ & $6,80 \%$ & $\mathrm{R} \$$ & $1.133 .467,07$ & $10,40 \%$ \\
\hline & $\begin{array}{l}\text { Receitas de } \\
\text { Transferência }\end{array}$ & $\mathrm{R} \$$ & $5.683 .483,23$ & $96,50 \%$ & $\mathrm{R} \$$ & $8.057 .433,05$ & $90,30 \%$ & $\mathrm{R} \$$ & $8.745 .583,95$ & $93,20 \%$ & $\mathrm{R} \$$ & $9.746 .802,12$ & $89,60 \%$ \\
\hline & $\begin{array}{l}\text { Total da Receita } \\
\text { Arrecadada }\end{array}$ & $\mathrm{R} \$$ & $5.890 .813,63$ & $100 \%$ & $\mathrm{R} \$$ & $8.926 .600,18$ & $100 \%$ & $\mathrm{R} \$$ & $9.382 .589,17$ & $100 \%$ & $\mathrm{R} \$$ & $10.880 .269,19$ & $100 \%$ \\
\hline \multirow{3}{*}{$\begin{array}{c}\text { Nova } \\
\text { Erechim }\end{array}$} & Receitas Próprias & $\mathrm{R} \$$ & $461.267,59$ & $5,50 \%$ & $\mathrm{R} \$$ & $1.632 .677,13$ & $13,30 \%$ & $\mathrm{R} \$$ & $2.069 .561,85$ & $15,70 \%$ & $\mathrm{R} \$$ & $1.698 .269,30$ & $12,20 \%$ \\
\hline & $\begin{array}{l}\text { Receitas de } \\
\text { Transferência }\end{array}$ & $\mathrm{R} \$$ & $7.927 .036,63$ & $94,50 \%$ & $\mathrm{R} \$$ & $10.662 .045,77$ & $86,70 \%$ & $\mathrm{R} \$$ & $11.085 .467,92$ & $84,30 \%$ & $\mathrm{R} \$$ & $12.252 .558,19$ & $87,80 \%$ \\
\hline & $\begin{array}{l}\text { Total da Receita } \\
\text { Arrecadada }\end{array}$ & $\mathrm{R} \$$ & $8.388 .304,22$ & $100 \%$ & $\mathrm{R} \$$ & $12.294 .722,90$ & $100 \%$ & $\mathrm{R} \$$ & $13.155 .029,77$ & $100 \%$ & $\mathrm{R} \$$ & $13.950 .827,49$ & $100 \%$ \\
\hline \multirow{3}{*}{$\begin{array}{l}\text { União Do } \\
\text { Oeste }\end{array}$} & Receitas Próprias & $\mathrm{R} \$$ & $231.619,52$ & $3,80 \%$ & $\mathrm{R} \$$ & $676.867,84$ & $7,30 \%$ & $\mathrm{R} \$$ & $1.661 .929,76$ & $14,70 \%$ & $\mathrm{R} \$$ & $703.445,87$ & $6,20 \%$ \\
\hline & $\begin{array}{l}\text { Receitas de } \\
\text { Transferência }\end{array}$ & $\mathrm{R} \$$ & $5.927 .579,65$ & $96,20 \%$ & $\mathrm{R} \$$ & $8.625 .568,16$ & $92,70 \%$ & $\mathrm{R} \$$ & $9.651 .575,18$ & $85,30 \%$ & $\mathrm{R} \$$ & $10.620 .451,96$ & $93,80 \%$ \\
\hline & $\begin{array}{l}\text { Total da Receita } \\
\text { Arrecadada }\end{array}$ & $\mathrm{R} \$$ & $6.159 .199,17$ & $100 \%$ & $\mathrm{R} \$$ & $9.302 .436,00$ & $100 \%$ & $\mathrm{R} \$$ & $11.313 .504,94$ & $100 \%$ & $\mathrm{R} \$$ & $11.323 .897,83$ & $100 \%$ \\
\hline
\end{tabular}

Fonte: Elaborado pelos autores

Observa-se na tabela 2, a relação de cada um dos municípios confrontando seus percentuais de receitas próprias e de transferências frente ao total de receitas arrecadadas. No caso do município de Águas de Chapecó, o mesmo vinha apresentando queda anual no tocante aos volumes de arrecadação própria, sendo que em 2013, apresentou significativa melhora. No município de Formosa do Sul pode se observar melhorias no volume de receitas próprias, tendo sido apontado uma pequena queda no ano de 2012, porém com o melhor resultado em termos percentuais em 2013, neste biênio houve elevação de 52,94\%, sendo de $6,8 \%$ para 10,4\%. Nova Erechim apresentou significativa progressão nos anos de 2011 e 2012, seguidas de uma pequena retração em 2013. O mesmo pode ser observado ao se analisar o município de União do Oeste.

Após o levantamento das receitas dos municípios estudados, apresenta-se o Gráfico 1, o demonstrativo do nível médio ${ }^{2}$ de dependência financeira destes municípios com relação ao volume total de receitas.

Gráfico 1 - Percentual médio de transferências 2010/2013.

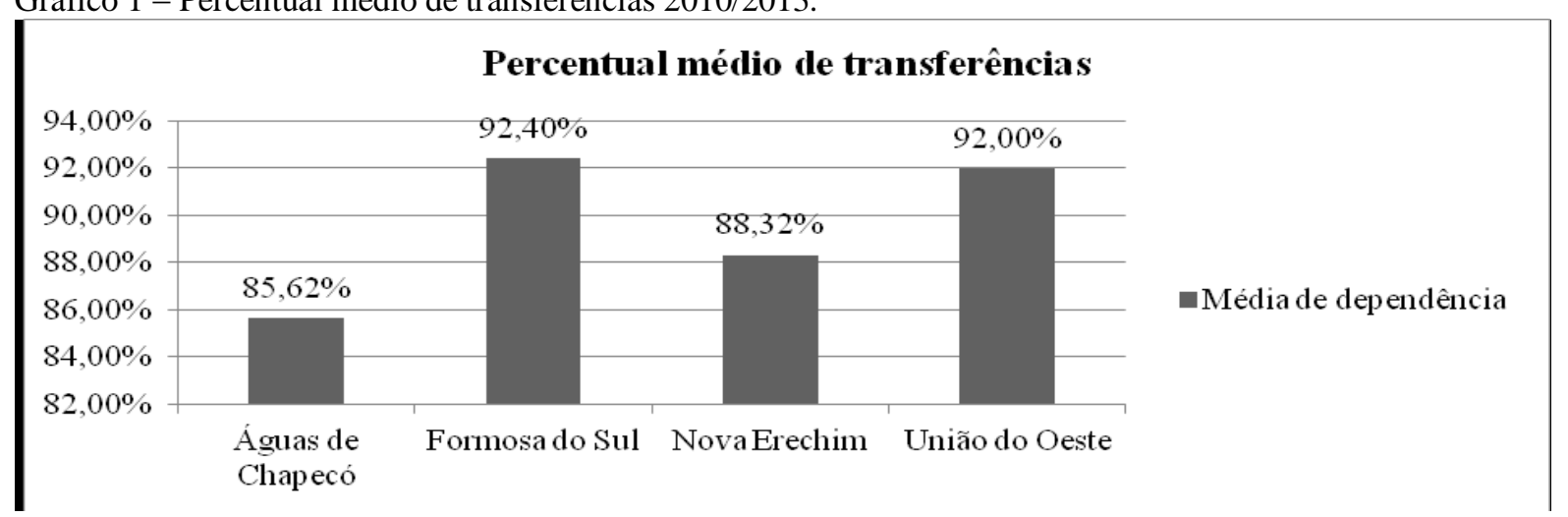

Fonte: Elaborado pelos autores

${ }^{2}$ Refere-se à soma dos percentuais anuais de transferências recebidas, divididos pelo número de anos em análise. 
Observa-se no Gráfico 1,que o município de Formosa do Sul apresenta maior nível médio de dependência financeira, seguido dos municípios de União do Oeste, Nova Erechim e Águas de Chapecó.

\subsection{Relacionamento do nível de desenvolvimento municipal de acordo com o grau de dependência de recursos}

Com vistas a relacionar o nível de desenvolvimento dos municípios estudados com seu grau de dependência de recursos, foi levantado inicialmente o Índice de Desenvolvimento Municipal Sustentável - IDMS, de cada um dos municípios, que podem ser identificados na tabela 3. O Índice de Desenvolvimento Municipal Sustentável - IDMS é uma das ferramentas do Sistema de Indicadores de Desenvolvimento Municipal Sustentável - SIDMS desenvolvido pela Federação Catarinense de Municípios - FECAM, que tem como objetivo avaliar os municípios segundo seu nível de desenvolvimento nos campos Sociocultural, Econômico, Ambiental e Político-institucional (FECAM, 2014). Salienta-se que tal índice é publicado a cada biênio, não sendo possível identificar tais índices para os demais anos.

Tabela 3 - Índice de Desenvolvimento Municipal Sustentável (IDMS) 2012/2014

\begin{tabular}{l|l|l}
\hline \multicolumn{1}{c|}{ Município } & $\mathbf{2 0 1 2}$ & $\mathbf{2 0 1 4}$ \\
\hline Águas de Chapecó & 0,650 & 0,548 \\
\hline Formosa do Sul & 0,697 & 0,719 \\
\hline Nova Erechim & 0,689 & 0,707 \\
\hline União do Oeste & 0,563 & 0,599 \\
\hline
\end{tabular}

Fonte: Elaborado pelos autores com base nos dados do Sistema de Indicadores de Desenvolvimento Municipal Sustentável - FECAM.

Observa-se na tabela 3, que apenas o município de Águas de Chapecó apresentou piora no IDMS, sendo uma queda de $15,70 \%$ com relação ao período anterior. Na tabela 4 são relacionados os volumes investidos em saúde e educação, apontando o percentual destes investimentos frente ao total de dispêndios.

Tabela 4 - Relação Despesas Totais X Despesas com Educação e Saúde 2010/2013

\begin{tabular}{|c|c|c|c|c|c|c|c|c|c|}
\hline \multicolumn{10}{|c|}{ DESPESAS POR FUNÇÃO } \\
\hline MUNICÍPIO & $\begin{array}{c}\text { TIPO DE } \\
\text { DESPESA }\end{array}$ & 2010 & $\%$ & 2011 & $\%$ & 2102 & $\%$ & 2013 & $\%$ \\
\hline \multirow{3}{*}{$\begin{array}{l}\text { Águas de } \\
\text { Chapecó }\end{array}$} & Saúde & $2.661 .351,75$ & 20,93 & $3.148 .130,31$ & 24,47 & $4.185 .753,58$ & 30,54 & $3.437 .691,43$ & 25,64 \\
\hline & Educação & $3.316 .113,38$ & 26,08 & $2.600 .498,87$ & 20,21 & $2.340 .250,18$ & 17,07 & $2.577 .057,25$ & 19,22 \\
\hline & TOTAL & 12.716.632,78 & & 12.864.447,29 & & 13.706.404,10 & & 13.410.115,26 & \\
\hline \multirow{3}{*}{$\begin{array}{c}\text { Formosa do } \\
\quad \text { Sul }\end{array}$} & Saúde & $1.417 .014,22$ & 17,83 & $1.760 .462,60$ & 18,62 & $1.872 .089,30$ & 17,48 & $2.144 .271,32$ & 20,10 \\
\hline & Educação & $1.633 .669,64$ & 20,55 & $1.815 .107,12$ & 19,20 & $2.842 .376,40$ & 26,54 & $2.133 .735,24$ & 20,00 \\
\hline & TOTAL & $7.949 .354,10$ & & $9.455 .101,30$ & & \begin{tabular}{|l|l|}
$10.711 .123,64$ \\
\end{tabular} & & 10.669.137,19 & \\
\hline \multirow{3}{*}{$\begin{array}{c}\text { Nova } \\
\text { Erechim }\end{array}$} & Saúde & $2.187 .294,06$ & 20,70 & $2.320 .622,65$ & 19,27 & $2.677 .117,97$ & 20,12 & $2.954 .239,94$ & 21,79 \\
\hline & Educação & $2.179 .228,25$ & 20,62 & $2.772 .306,22$ & 23,02 & $2.831 .341,39$ & 21,28 & $2.993 .678,00$ & 22,08 \\
\hline & TOTAL & $10.568 .133,56$ & & 12.041.653,12 & & 13.307.363,97 & & 13.557.370,85 & \\
\hline \multirow{3}{*}{$\begin{array}{l}\text { União do } \\
\text { Oeste }\end{array}$} & Saúde & $1.584 .957,07$ & 18,47 & $1.803 .099,76$ & 20,87 & $2.460 .704,00$ & 21,36 & $2.482 .242,55$ & 22,45 \\
\hline & Educação & $1.568 .759,65$ & 18,28 & $1.823 .249,50$ & 21,10 & $2.322 .418,65$ & 20,16 & $2.129 .574,66$ & 19,26 \\
\hline & TOTAL & $8.581 .380,14$ & & $8.639 .874,76$ & & $11.520 .144,02$ & & $11.057 .538,63$ & \\
\hline
\end{tabular}

Fonte: Elaborado pelos autores 
Após a verificação dos valores investidos em saúde e educação, nos municípios estudados, apresenta-se um gráfico demonstrativo do nível médio ${ }^{3}$ destes investimentos frente ao total de despesas de cada um dos municípios.

Gráfico 02 - Percentual médio de transferências 2010/2013.

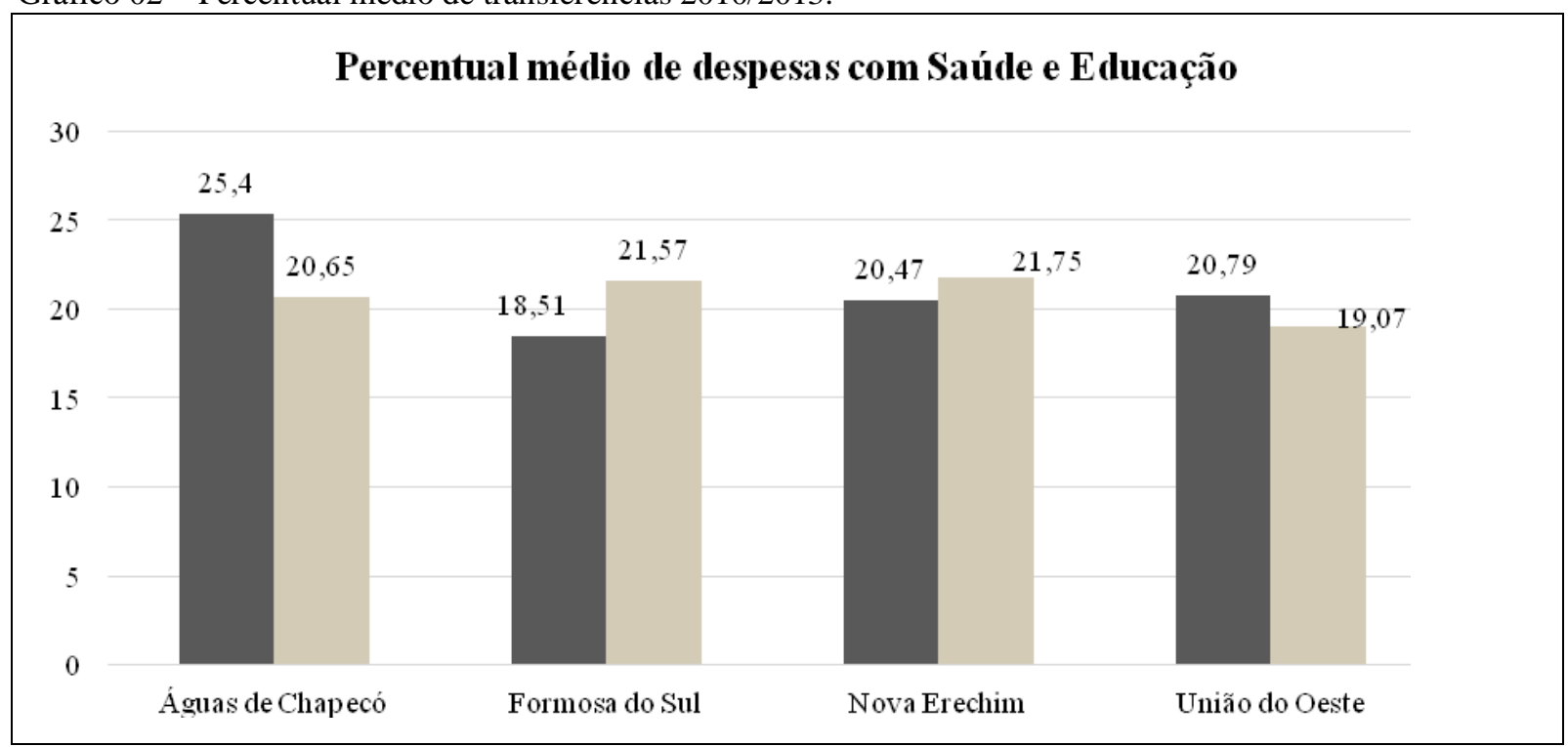

Fonte: Elaborado pelos autores

Ao confrontar o percentual médio de transferências (gráfico 01), com o IDMS destes municípios em 2014 (tabela 6), é possível observar que o maior IDMS é do município de Formosa do Sul, município com maior percentual médio de transferências intergovernamentais. Também, observa-se que o menor IDMS é registrado no município com menor percentual de transferências, sendo de Águas de Chapecó, podendo representar uma relação direta entre os indicadores, quanto maior o percentual de transferências, maior o IDMS, o que não ocorre no caso de Nova Erechim e União do Oeste.

No entanto, os dados das tabelas 2, 3, 4 e 5 permitem reconhecer que no último biênio Nova Erechim e União do Oeste apresentam aumento no nível de dependência de transferências, assim como acréscimo no IDMS, o mesmo não é averiguado nos demais municípios. A partir destas constatações, não é possível estabelecer relação direta entre os indicadores, tendo em vista que o comportamento das variáveis não é idêntico nos diferentes municípios.

Ao comparar os volumes de investimento em saúde e educação no último biênio, constatou-se em todos os casos, uma relação direta com o percentual de transferências recebidas por estes municípios. Em Águas de Chapecó, o volume de transferências sofreu queda de $3,74 \%$, assim como o volume de investimentos em saúde e educação apresentou retração de 5,78\%, o mesmo ocorre em Formosa do Sul, com queda de 3,86\% e 8,91\% respectivamente. Ao analisar os dados do município de Nova Erechim, há um aumento de $4,15 \%$ no percentual de transferências e $5,97 \%$ no percentual de investimentos em saúde e

${ }^{3}$ Refere-se à soma dos percentuais anuais de despesas com saúde e educação, divididas pelo número de anos em análise. 
educação, essa relação de aumento também é verificada no município de União do Oeste, que apresenta um aumento de 9,96\% nas transferências recebidas e $1,81 \%$ no percentual de investimentos em saúde e educação. Constata-se, ao final desta análise, que apesar da relação direta, as variáveis não retraem ou avançam na mesma proporção.

\subsection{Discussão dos resultados}

Com base na análise dos dados da pesquisa, percebe-se a inexistência de relação direta entre os indicadores avaliados. Isso vem ao encontro ao entendimento de Siedenberg (2006), que afirma a existência de particularidades supondo diferentes localidades, ou seja, o desenvolvimento acontece em diferentes períodos de tempo e espaço, apontando apenas algumas características de um determinado momento do processo de mudanças.

Também, observou-se que na maioria dos casos, quando houve aumento no volume de repasse de receitas, os níveis de investimento em saúde e educação, bem como o índice de Desenvolvimento Municipal Sustentável aumentaram, o que por sua vez não implica no menor desenvolvimento daqueles municípios cuja autonomia financeira seja maior.

A fim de que estes municípios tenham condições de aportar e contribuir para o desenvolvimento regional, se faz necessário em especial o envolvimento de diferentes atores sociais no planejamento, desenvolvimento e fiscalização de políticas públicas, inclusive aproveitando o aporte da Associação de Municípios nesta tarefa. A formação de consórcios entre municípios de pequeno porte possibilita a diversificação das atividades econômicas, o que faz com que cada município possa melhor explorar suas potencialidades, a partir da intensificação destes laços de solidariedade territoriais.

As ações supracitadas podem ser consideradas como mecanismos potenciais de modificação do grau de dependência da transferência de recursos, em função da promoção e diversificação das atividades econômicas, desta forma gerando um ciclo de desenvolvimento mais equitativo e menos assimétrico. Entretanto, destaca-se que tais medidas exigem ações de curto, médio e longo prazo, pois o resultado das mesmas não seria apenas imediato.

Por fim, salienta-se que o desenvolvimento regional não se cristaliza apenas por ações articuladas neste ambiente, mas a partir da soma de ações canalizadas localmente, de forma sistemática implicam na modificação da estrutura socioeconômica regional.

\section{CONSIDERAÇÕES FINAIS}

O propósito da presente pesquisa foi identificar o nível de desenvolvimento regional frente à problemática da sustentabilidade econômico-financeira dos quatro municípios selecionados na região da AMOSC, por meio da identificação dos níveis de dependência econômico-financeira destes municípios, frente às transferências governamentais.

A análise demonstrou que existe um viés entre o nível de dependência e o desenvolvimento de cada um destes municípios, pois aqueles com maiores volumes de transferências, majoritariamente são aqueles com maior nível de desenvolvimento. Constatouse, sobretudo, que apesar de haver relação direta entre as variáveis, essa condição não se 
sustenta em diferentes temporalidades, em função de que cada município tem suas particularidades, inclusive são influências por fatores externos regionais.

Este estudo contribui para que os gestores municipais percebam que o grau de dependência de transferências intergovernamentais, não necessariamente implica em maior ou menor grau de desenvolvimento. Isso ocorre mais efetivamente pela capacidade de articulação entre agentes públicos, entidades e sociedade, no sentido de ampliar as possibilidades de desenvolvimento, inclusive, que poderia ter impactos significativos na região, a partir da difusão sistemática no interior dos municípios, criando também a potencialidade de laços de solidariedade regional.

Essas conclusões pretendem contribuir no sentido de entender que a capacidade de geração de receitas próprias, não necessariamente implica em maiores níveis de desenvolvimento, ou seja, o desenvolvimento vai além da autonomia econômica financeira dos municípios, implicando de certa forma, no preparo destes em melhor estabelecer e gerenciar suas políticas públicas, atentando para a necessidade local.

Dentre as limitações do estudo, pode-se citar a realização baseada somente em dados secundários. Sugere-se que outros estudos repliquem esta pesquisa ampliando os instrumentos utilizados e ainda a amplitude espacial, com municípios com características diferentes. Isso permitirá vislumbrar uma relação mais concisa entre as variáveis. Além disso, recomenda-se identificar as políticas públicas desenvolvidas em cada um dos municípios como aporte ao desenvolvimento local.

Outra potencialidade desta modalidade de pesquisa, diz respeito à formação de redes de cooperação entre os municípios, para a gestão de políticas públicas, e demais investimentos, especialmente aquelas estruturais e que servem de base ou aporte ao desenvolvimento e que não teriam a função de atender apenas a unidade municipal. Desta forma, por considerar que são de pequeno porte, teriam condições mais adequadas de competitividade regional, contribuindo para a redução gradativa de suas assimetrias, em contraponto aos cenários atuais, inclusive elencados nos referências teóricos desta pesquisa.

\section{REFERÊNCIAS}

BECKER, Dinizar F; DALLABRIDA, Valdir Roque. Dinâmica Territorial do

Desenvolvimento. Santa Cruz do Sul: EDUNISC 2003.

BENKO, Georges. A ciência regional. Portugal: Celta, 1999.

BERNARDY, Rógis Juarez; ZUANAZZI, Jeancarlo; MONTEIRO, Ricardo Rodrigues. Território, planejamento e gestão: um estudo do Oeste Catarinense a partir da região da AMOSC. Chapecó: FIE, 2008.

BUGS, João Carlos. Abordagem estratégica dos processos de desenvolvimento socioeconômico regional: o caso do corede VRP. 2011. Dissertação (Mestrado) Universidade de Santa Cruz do Sul, Santa Cruz do Sul. 
CÂNDIDO, Gesinaldo Ataíde. A formação de redes interorganizacionais como mecanismo para geração de vantagem competitiva e para promoção do Desenvolvimento Regional: O papel do estado e das políticas públicas neste cenário. Revista Eletrônica de Administração, Porto Alegre, v. 8, jul./ago. 2002. Disponível em:

<http://www.read.ea.ufrgs.br/edicoes/pdf/artigo_95.pdf>. Acesso em 10 mai. 2014.

CERVO, Amado Luiz; BERVIAN, Pedro Alcino. Metodologia Cientifica. 4. ed. São Paulo: Makron Books, 1996.

CORRÊA, Roberto Lobato. Trajetórias geográficas. Rio de Janeiro: Bertrand Brasil, 1997.

FEDERAÇÃO CATARINENSE DE MUNICÍPIOS -FECAM. Metodologia IDMS. Disponível em: < http://indicadores.fecam.org.br/cms/pagina/ver/codMapaItem/621>. Acesso em: 10 mai.. 2014.

FEDERAÇÃO CATARINENSE DE MUNICÍPIOS -FECAM. Sistema de Indicadores de Desenvolvimento Municipal Sustentável. Disponível em: < http://indicadores.fecam.org.br/cms/pagina/ver/codMapaItem/621>. Acesso em: 10 mai.. 2014.

FILIPPIM, Eliane Salete; ABRUCIO, Fernando Luiz. Quando descentralizar é concentrar poder: O papel do governo estadual na experiência catarinense. Revista de Administração Contemporânea, Curitiba, v. 14, n. 2, p. 212-228, mar./abr. 2010. Disponível em: http://www.anpad.org.br/rac. Acesso em 28 mar. 2014.

FILIPPIM, Eliane Salete; RÓTULO, Daniel. Governança, participação social e diálogo federativo: O caso de Santa Catarina. In: RANDOLPH, Rainer; TAVARES, Hermes Magalhães (Org.). Política e planejamento regional: Uma coletânea. Brasília: Movimento, 2013. Cap. 3.

GIL, Antonio Carlos. Métodos e técnicas de pesquisa social. 6. ed. São Paulo: Atlas, 2008.

IBGE. Censo Demográfico 2010. Disponível em: <http://www.ibge.gov.br>. Acesso em: 25 mar. de 2014.

INEP. Censo Escolar. Disponível em: <http://portal.inep.gov.br/basica-censo>. Acesso em: 07 jun. de 2014.

LOPES. A. Simões. Desenvolvimento regional: problemática, teoria, modelos. 4 ed. Lisboa: Fundação Calouste Gulbenkion, 1995.

MARCONI, M. A.; LAKATOS, E. M. Fundamentos de Metodologia Científica. 5. ed. São Paulo: Atlas 2003.

NADAL, Raul de; BERNARDY, Rógis Juarez. Regionalização e Planejamento do Desenvolvimento. Diário do Iguaçu, Chapecó, p. 10E, 12 abr. 2002.

ORLOWSKI, Rosemari Fátima. Indicadores de Desenvolvimento socioeconômico na região da AMOSC-Associação dos municípios do Oeste de Santa Catarina. Disponível em: http://www.sober.org.br/palestra 
/2/922.pdf. Acesso em 02 abr. 2014.

SANTOS, A. M. S. P. Município, descentralização e território. Rio de Janeiro: Forense, 2009.

SECRETARIA DO TESOURO NACIONAL. Portaria no 350, de 18 de junho de 2010. Procedimentos Contábeis Orçamentários. Disponível em: <http://www3.tesouro.gov.br/hp/downloads/Port_350_18062010_Ementario_Receita.pdf>. Acesso em: 26 maio 2014.

SIEDENBERG, Dieter Rugard. Dicionário Desenvolvimento Regional. Santa Cruz do Sul: EDUNISC, 2006.

. Desenvolvimento: ambiguidades de um conceito difuso. Revista Desenvolvimento em Questão, Unijuí, v.2, n. 3, jan./jun. 2004. Disponível em https://www.revistas.unijui.edu.br/index.php/desenvolvimento emquestao/article/view/87/44>. Acesso em 01 abr. 2014.

YIN, Robert K. Estudo de Caso: planejamento e métodos. Porto Alegre: Bookman, 2001. 